\title{
A Comparison of the Dynamic Performance of Conventional and Ternary Pumped Storage Hydro
}

\author{
Soumyadeep Nag ${ }^{1, *(\mathbb{D})}$, Kwang Y. Lee ${ }^{1}$ and D. Suchitra ${ }^{2}$ \\ 1 Department of Electrical and Computer Engineering, Baylor University, Waco, TX 76706, USA; \\ kwang_y_lee@baylor.edu \\ 2 Department of Electrical Engineering, SRM University, Kattankulathur 603203, India; \\ suchitra.d@ktr.srmuniv.ac.in \\ * Correspondence: Soumyadeep_Nag@baylor.edu; Tel.: +1 2544207420
}

Received: 31 July 2019; Accepted: 10 September 2019; Published: 12 September 2019

\begin{abstract}
With decreasing costs of renewable energy harvesting devices, penetration of solar panels and wind turbines have increased manifold. Under such high levels of penetration, coping with increased intermittency and unpredictability and maintaining power system resiliency under reduced inertia conditions has become a critical issue. Pumped storage hydro (PSH) is the most matured and economic form of storage that can serve the purpose of capacity for over 4 to $8 \mathrm{~h}$. However, to increase network inertia and add required flexibility to low inertia power systems, significant paradigm shifting modifications have been engineered to result in the development of Ternary PSH (TPSH). In this paper a test system to consider governor interaction is constructed. The dynamic models of conventional PSH (CPSH) and TPSH are constructed and integrated to the test system to examine the effect of CPSH and TPSH in the hydraulic short circuit (TPSH-HSC). The ability and the effect of mode change (from pump to turbine) without the loss synchronism of TPSH has also been examined. Results display the superior capability and effect of TPSH with its HSC capability to contribute to frequency regulation during pumping mode and the effect of rapid mode change, as compared to its primitive alternative, $\mathrm{CPSH}$.
\end{abstract}

Keywords: energy storage; pumped storage hydro; ternary pumped storage hydro; dynamic simulation; dynamic modeling; inertia; renewable energy; power system

\section{Introduction}

\subsection{Problem Statement}

With the introduction of large-scale renewable energy sources (RES), power system inertia is dropping [1]. The key underlying reason behind this is the fact that the inclusion of renewables in the schedule removes steam-driven synchronous generators out of the schedule. The removal of synchronous generators from the schedule simultaneously removes the services that are being provided to the grid by the thermal generators. These services include the inertia response and reserve, primary control and reserve, and secondary control and reserve. To exacerbate the situation, many thermal power plants that are now aging, are being decommissioned. From press releases, these aging thermals are planned to be replaced mostly by combined cycle gas turbine plants [2] but some are planned and being converted into solar farms [3-5]. Apart from aging, the other cause of retirement is the cost of operation. Especially in regions with high renewable penetration the cost of operating an outdated coal-based or gas-based plant can be comparatively high. Among other reasons for early retirement is that the plant has become unreliable or it does not meet the emissions standard of the region [6].

In such a low inertia system, a significant frequency deviation (that can be caused by the loss of a generator) may cause highly configured inverters to provide virtual support through virtual 
synchronous generation, but most others (especially small roof-top photovoltaic (PV) units) are programmed to disconnect from the grid and cause further deviation in frequency [7]. It is obvious that gas turbine based peaking plants can be deployed but, adding gas turbines diminishes the purpose of renewable energy completely as they are a key source of greenhouse gases and $\mathrm{NO}_{\mathrm{x}}$ and $\mathrm{SO}_{\mathrm{x}}$ pollutants.

Energy storage is a critical component of future power systems. If managed efficiently, energy storage can provide several beneficial services like cost savings through avoided capacity investments, curtailment mitigation and increased and firmed renewable penetration, ancillary and capacity reserves, black start capabilities, load shifting, transmission support, and congestion relief among a few others [8]. As such, modern large-scale green initiatives and investments are inclined more towards solar + storage or wind + storage rather than having the RES only [9]. A study conducted in [10] states that the size of required storage increases almost linearly as renewable energy penetration increases. However, there is an optimal size of energy storage beyond which penetration levels off. This was observed in two different systems examined and the authors arrived at the conclusion that it was $70 \%$ to $20 \%$ of the daily average demand.

Pumped storage is by far the most matured form of grid scale energy storage with discharge durations ranging from 1 to $6 \mathrm{~h}$. PSH can provide synchronous inertia and primary and secondary frequency regulation services. Pumped storage hydro (PSH) relies on gravity as the driving force. When the price of electricity is less than a carefully selected optimum value, the plant pumps water to an elevated reservoir. When there is a shortage of power on the grid, it unleashes the water stored in the reservoir down to the turbines to produce energy and delivers it to the grid. This describes the basic operation of the PSH plants that has been prevalent for the past several decades. However, this basic use of price differentials or arbitrage is no more than enough to meet today's power system's needs. The need for power system resiliency and flexibility has caused power system operators to look for storage devices that can be deployed for long duration and serve system regulatory needs.

Around the world, there is $170 \mathrm{GW}$ of installed PSH plants [11] that includes $3211 \mathrm{MW}$ as ternary PSH (TPSH) and $9545 \mathrm{MW}$ as adjustable speed PSH (ASPSH) but the $157 \mathrm{GW}$ is still conventional PSH (CPSH). The main drawbacks of CPSH include the pump mode inflexibility (which is because of the use of a synchronous machine) apart from which the slow mode changing time and low part-load generation efficiencies are important short-comings of CPSH.

To overcome these drawbacks, PSH technology has seen a paradigm shift during the past 10 years with technological advancements in the fields of electromechanical design and construction and power electronics. Two such remarkable modifications are the TPSH and the ASPSH. Given a majority of PSH plants are at the end of life or above their half-life [12], many existing PSH plants are considering the upgrade during renovations and new PSH plants are looking forward to these modified units.

Moreover, markets around the world are creating opportunities for energy storage to participate in capacity and regulation markets. Realizing the benefits and obstacles of widescale use of energy storage, Federal Energy Regulatory Commission (FERC) order-841 issued on 15 February 2018 in USA directs regional operators and independent system operators (ISOs) e.g., California ISO, New York ISO, Pennsylvania-New Jersey-Maryland Interconnection (PJM), etc. to remove barriers and lay down legal foundations for the participation of energy storage in the concerned region's wholesale markets, i.e., the capacity market, energy market, and ancillary service markets [13]. On the face of increased penetration from renewable energy, regional markets have realized the potential of energy storage and have responded to FERC order-841 through their compliance plans [14]. Most of these ISOs are now in the process of developing participation models for energy storage systems while trying to comply with the directives of FERC order-841. As of now, except CAISO, most other ISOs are either partially or completely non-compliant with FERC order-841. Most of these regional operators need to figure out a market structure or model in which the energy storage devices can participate [15]. 


\subsection{A General Classification of PSH}

Pumped storage facilities can be classified as a closed or open circuit. Open-circuit PSH refers to those plants that have their lower reservoir connected to a river or a sea. Closed-circuit PSH refers to those plants that have no other source of water except that which is already stored in the upper and lower reservoirs. Pumped storage facilities can be further classified into sub-surface and surface reservoir types. While the surface reservoir is the most common type of $\mathrm{PSH}$, the sub-surface reservoir type, one or more reservoirs, and the powerhouse will be underground. This concept allows the usage of abandoned mines, wells, shelters, and shafts to be utilized as a reservoir [16].

\subsection{Other Notable Modifications of PSH}

Although PSH is a solution to the ever-fluctuating renewable energy resources, many regions in the world do not have the geographic ability required to build a PSH. To overcome this problem, the following solutions have been devised:

1. STENSEA (stored energy in the sea) where a concrete tank, equipped with a pump-turbine-generator system, is placed at the bottom of the ocean bed. This structure generates electricity when filled and uses electricity to pump water out of the system [17]. The concept is now at a technology readiness level between 5 and 6 . It has been successfully tested in a lab, which was followed by a similar environment testing in a lake.

2. Wind turbines with water storage are a recent invention and are the only source where the two forms of energy are physically integrated. Here wind turbines pump water up their tower and into tall tanks beside them when excess energy is available. When energy is required these tanks are emptied through a pump-turbine to generate electricity [18]. The pilot project is already completed for this concept. Four such turbines are in operation in Germany's Swabian-Franconian forest with turbines supplied by General Electric (GE) renewable energy.

3. Gravity power modules implement the principle of a hydraulic jack and gravity to generate electricity. A very heavy mass slides down a hole in the ground pushing water below the mass into the pump-turbine (through a narrow hole) to generate electricity. The same pump turbine is used to pump the mass up to its initial level to store excess energy. [19].

This work contributes to the construction of dynamic models of a governor-turbine system for TPSH and examines the benefits of TPSH over CPSH. The dynamic model is constructed to display the generating, pumping, and hydraulic short circuit mode. The authors have considered an IEEE 9 bus test system and evaluated the effect of significant PV penetration by simulating an increase in the load event. Simultaneously, the authors have examined the benefit of TPSH over CPSH in enhancing system resiliency in terms of system frequency profile. This paper is divided into five sections. Section 2 describes ASPSH and TPSH and details the modes of operation of the TPSH. Section 2 also details some differences between ASPSH and TPSH. Section 3 presents the dynamic modeling of TPSH. Section 4 presents the test system for the study along with certain simulation details and Section 5 presents the results of the study followed by a brief description of the test case and results.

\section{Advanced Pumped Storage Hydro Plants}

\subsection{Adjustable Speed PSH plants (ASPSH)}

There are two variants of adjustable speed PSH (ASPSH) as displayed in Figure 1. 

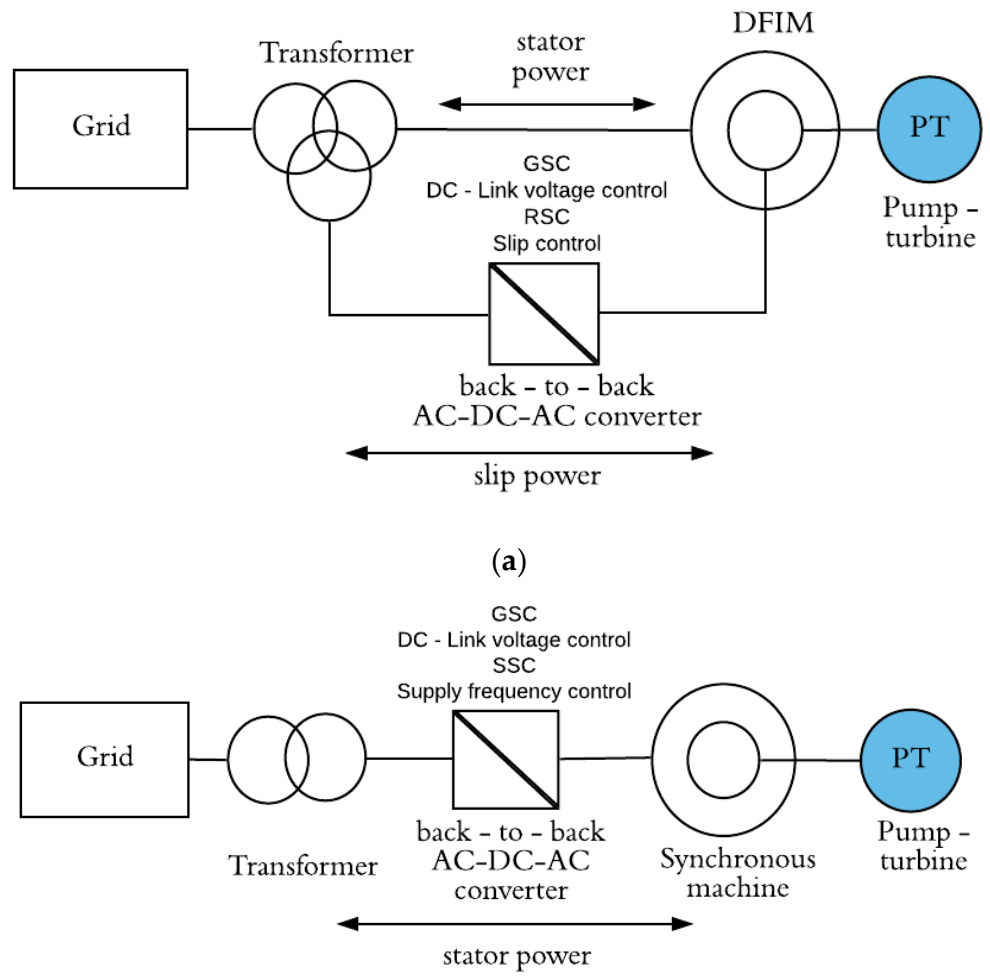

(b)

Figure 1. Adjustable speed pumped storage hydro: (a) Employing doubly fed induction machine (DFIM) with a rotor side converter; and (b) employing synchronous machine. GSC-Grid side converter, SSC-Stator side converter, RSC-rotor side converter.

Type-1: Here, the plant uses a doubly fed induction machine (DFIM) with a reversible pump-turbine, instead of the conventional fixed-speed synchronous machine coupled with a reversible pump-turbine [20]. This version is inspired from type-3 wind turbines. The back-to-back converter has two separate parts namely, the grid-side converter (GSC) and the rotor-side converter (RSC). The RSC controls the torque (real power) and the reactive power exchanged with the grid through the stator. The GSC regulates the DC-link voltage and attempts to keep it constant. By utilizing this configuration, the speed of the machine can be controlled, which will in turn control the power consumed during the motoring phase or generating phase.

Type-2: Here, a fully fed converter is coupled with a synchronous machine, which is coupled with a reversible pump-turbine. This is inspired from the type- 4 wind turbines. This plant implements a synchronous machine with the stator connected to the grid via a back-to-back voltage source converter and the required filter. The rotor is extended to provide excitation. The stator-connected converter helps to control the speed and hence the power transfer to or from the machine. The excitation is usually a controller to maintain a fixed stator voltage. Here, the size of the converter required is equal to that of the machine and hence the floor space requirements are more than that of type- 1 , which translates into increased capital investment cost. Like type-1, generation and pumping speeds can be varied by the converter system. This configuration allows the operator to bypass the converter generation operation while including it during the pumping operation, which adds to network regulation.

\subsection{Ternary Speed PSH Plants (Synchronous Speed)}

A TPSH consists of a turbine, pump, and a synchronous machine on the same shaft. The turbine can be a Francis turbine or a Pelton wheel depending upon the available head. The pump is usually a single or multi-stage centrifugal pump. The three systems are separated by two clutches on each side 
of the salient-pole synchronous machine. The turbine and the pump share the same penstock, which also implies that the TPSH system can operate only in the pumping mode or the generating mode at any instant of time.

\subsubsection{Generator Mode of TPSH}

Figure 2a illustrates the generator mode. During the generation mode, the TPSH plant operates like a conventional hydro plant, where the pump-side clutch $c 2$ separates (status 0 ) the pump from the shaft while c1 connects the turbine to the shaft (status 1). A governor is used to regulate the speed and power of the generator. The turbine valve $(\mathrm{Vt})$ remains open and the pump valve $(\mathrm{Vp})$ remains closed.

\subsubsection{Pump Mode}

Figure $2 \mathrm{~b}$ displays the pump mode operation. During the pumping mode, the turbine remains disconnected from the shaft using clutch $\mathrm{c} 1$ (status 0 ) and the pump is connected to the shaft via $\mathrm{c} 2$ (status 1). The turbine valve Vt remains closed for pure pumping mode.

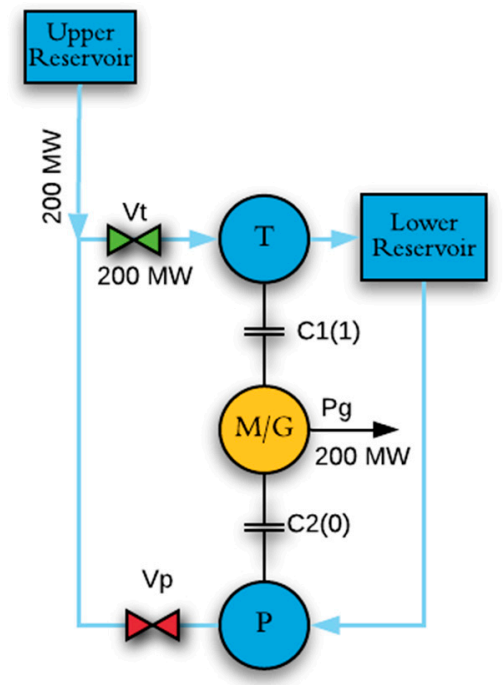

(a)

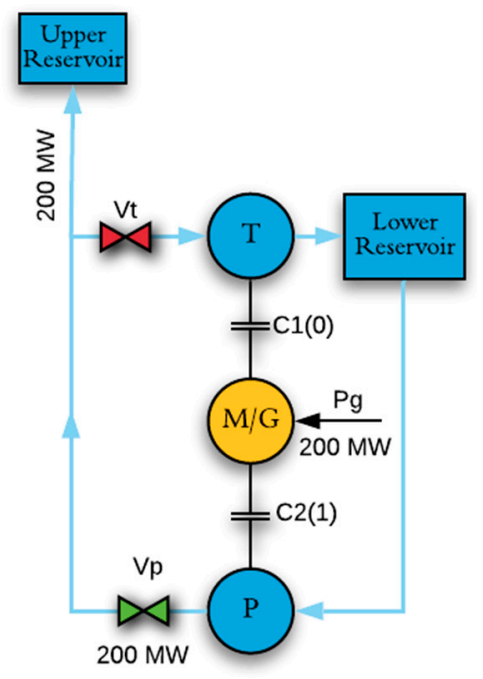

(b)

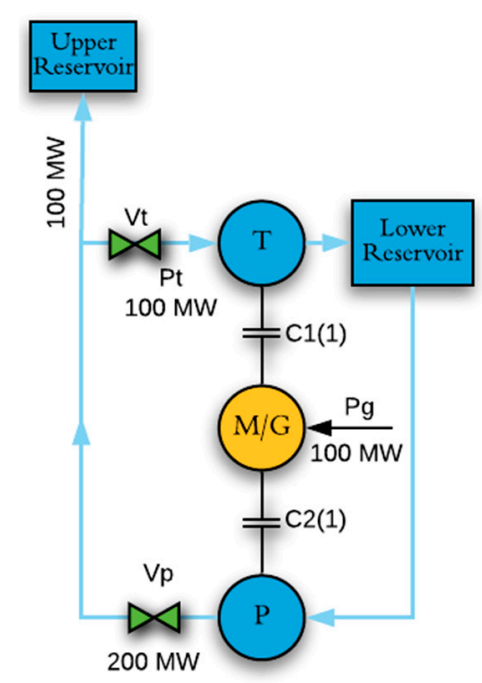

(c)

Figure 2. Modes of operation of ternary pumped storage hydro (TPSH) with the status of valves and clutches: (a) Generator mode; (b) pure pump mode; and (c) hydraulic short circuit mode (HSC). Clutches $\mathrm{c} 1$ and $\mathrm{c} 2$ are either in open mode (status 0 ) or closed mode (status 1 ). The turbine valve Vt and pump valve $\mathrm{Vp}$ are either in the open mode (status green) or in the closed mode (status red).

\subsubsection{Hydraulic Short-Circuit Mode}

Figure 2a displays the hydraulic short-circuit mode (HSC) mode. During the HSC mode, a part of (or all) the water pumped by the pump is transferred to the turbine by opening Vt while Vp remains open. Both the clutches $\mathrm{c} 1$ and $\mathrm{c} 2$ also connect the turbine and pump to the shaft. This in turn causes the turbine to produce torque that is supplied to the shaft. This mechanical torque from the turbine will reduce the current drawn from the grid while still rotating at the synchronous speed. The remaining part of the water is pumped up to the upper reservoir.

The hydraulic short circuit mode takes advantage of the fact that the head generated by the pump is either equal or greater than that of the upper reservoir at any instant of its operation as long as the pump rotates at synchronous speed. The turbine being connected right next to the pump experiences the pump generated head, which is in fact the rated head of the turbine, which enables it to generate power.

In Figure 2a $100 \mathrm{MW}$ of electrical power is consumed from the grid. Since the pump rotates at synchronous speed it generates rated head and part of the discharge at rated head (worth $100 \mathrm{MW}$ ) 
is supplied to the turbine, which generates equivalent mechanical power. Hence the net work done, which is found through the amount of water raised to the upper reservoir is only 100 MW while 100 MW is supplied to the shaft.

The use of HSC allows the plant to follow power commands from the automatic generation control (AGC) and provide a secondary frequency. It also allows the plant to respond to network frequency disturbances and provide primary frequency control. Table 1 highlights the pros and cons of the advanced pumped storage units in comparison to CPSH.

Table 1. Comparison of adjustable speed PSH (ASPSH) and TPSH with respect to conventional $\mathrm{PSH}(\mathrm{CPSH})$.

\begin{tabular}{|c|c|c|}
\hline Attribute & ASPSH & TPSH \\
\hline Converter requirement & $\begin{array}{c}\text { Type } 1 \text { requires converters rated } \\
10 \% \text { of the machine, } \\
\text { Type } 2 \text { requires fully } \\
\text { rated converters }\end{array}$ & $\begin{array}{l}\text { Does not require converters for } \\
\text { grid interfacing. }\end{array}$ \\
\hline Efficiency & $\begin{array}{l}\text { Peak efficiency will be reduced } \\
\text { compared to the CPSH. Part-load } \\
\text { efficiencies can be improved with } \\
\text { speed variation. }\end{array}$ & $\begin{array}{c}\text { Peak efficiency same as that of CPSH. } \\
\text { Part-load efficiencies are better than CPSH as } \\
\text { TPSH uses a pure turbine instead of } \\
\text { pump-turbine. }\end{array}$ \\
\hline Mode-change time & $\begin{array}{l}\text { Time required to change from the } \\
\text { pumping to generating mode is in } \\
\text { the order of a few minutes. }\end{array}$ & $\begin{array}{l}\text { Time required to change from the pumping to } \\
\text { generating mode is significantly reduced. } \\
\text { Seamless mode change can be performed as } \\
\text { shaft rotated in a single direction. }\end{array}$ \\
\hline Shaft inertia & Same as CPSH. & $\begin{array}{l}\text { The shaft consists of the electrical machine } \\
\text { and the separate pump and a separate turbine. } \\
\text { Thus, in the hydraulic short circuit mode the } \\
\text { shaft has comparatively more inertia. }\end{array}$ \\
\hline Design optimization & $\begin{array}{l}\text { The pump-turbine is optimized as } \\
\text { a pump and then as a turbine. } \\
\text { Thus, during off-design operating } \\
\text { conditions as a turbine, the } \\
\text { efficiency decreases drastically. }\end{array}$ & $\begin{array}{l}\text { The pump and the turbine can be separately } \\
\text { optimized. This leads to higher } \\
\text { cycle efficiency. }\end{array}$ \\
\hline Frequency regulation & $\begin{array}{l}\text { Possible but only with } \\
\text { auxiliary control. }\end{array}$ & Fully capable. \\
\hline $\begin{array}{l}\text { Natural inertia and synchronous } \\
\text { frequency response }\end{array}$ & $\begin{array}{l}\text { The converter's natural tendency } \\
\text { is to act against grid frequency. } \\
\text { The direction of change of speed } \\
\text { and change of torque (and hence } \\
\text { the current) are opposite. }\end{array}$ & $\begin{array}{l}\text { Its natural tendency is to support the grid } \\
\text { frequency, which allows the machine to slow } \\
\text { down and release energy into the network. }\end{array}$ \\
\hline Range of flexibility & $\begin{array}{l}\text { Limited range of flexibility is } \\
\text { available. Range is limited by } \\
\text { cavitation limits and } \\
\text { converter size. }\end{array}$ & $\begin{array}{l}\text { Higher range of flexibility due to the use of a } \\
\text { separately optimized turbine and pump. }\end{array}$ \\
\hline $\begin{array}{l}\text { Smooth start capability for } \\
\text { pumping mode. }\end{array}$ & $\begin{array}{l}\text { Possible but only with } \\
\text { auxiliary control. }\end{array}$ & $\begin{array}{c}\text { Fully capable as the pump can be started with } \\
\text { the turbine. }\end{array}$ \\
\hline Possibility of failure & $\begin{array}{l}\text { Increases as the number of } \\
\text { components increases. }\end{array}$ & $\begin{array}{l}\text { Low because the number of components is } \\
\text { comparatively lower. }\end{array}$ \\
\hline
\end{tabular}

\section{Dynamic Modeling of TPSH}

To realize the above-mentioned functionalities of the TPSH plant, the following model has been adapted from [21] and [22]. Compared to [22], [21] gives a better idea of pump performance but provides a model that simulates the turbine and pump modes separately. While [22] does unite the pump and turbine models, however, there are certain model corrections that need to be noticed. First, there is no need for a power distribution coefficient as the pump does not participate in reference tracking. Secondly, the integration of $\Delta h$ to generate the discharge should be negative to realize the effect of the pump. Finally, the pump and turbine mechanical powers are added together, which should 
be a subtraction operation instead. Apart from that, the fact that the system has variable inertia has not been stated or accommodated by the model in [21] or [22]. This work is not focused on correcting these flaws but tries to incorporate the required corrections to regenerate the dynamics of the plant.

Figure 3 displays the schematic of the governor turbine system. The penstock dynamics for the pump and the turbine and their interaction can be modeled by [23]:

$$
\begin{gathered}
\frac{d q_{t}}{d t}=\frac{H_{t}-h-h_{l}}{T w}, \\
\frac{d q_{p}}{d t}=\frac{-\left[H_{p}-h-h_{l}\right]}{T w},
\end{gathered}
$$

where $H_{t}, H_{p}, h$, and $h_{l}$ define the available head for the turbine, generated head by the pump, head at turbine entrance $q_{\text {base }}$, and head loss due to friction as $h_{l}=f_{p} Q^{2}$, and Tw is the water starting time constants to accommodate the interaction between the turbine and pump or vice versa.

Equations (1a) and (1b) relates head and discharge without accommodating any interactions and can be generalized as:

$$
\frac{d q}{d t}=\frac{\Delta h}{T w}
$$

where, the water starting time constant is given as:

$$
T w=\frac{L q_{\text {base }}}{A g h_{\text {base }}} .
$$

Here, $L, q_{\text {base }}, A, g$, and $h_{\text {base }}$ define the length of the penstock, base flow $(=1)$, cross section of the penstock, the gravitational constant and the base head (=1).

The above model can also be represented in matrix form as:

$$
\left[\begin{array}{cc}
T w_{t t} & T w_{t p} \\
T w_{p t} & T w_{p p}
\end{array}\right]\left[\begin{array}{c}
\frac{d q_{t}}{d t} \\
\frac{d q_{p}}{d t}
\end{array}\right]=\left[\begin{array}{c}
\Delta h_{t} \\
\Delta h_{p}
\end{array}\right] .
$$

Here $T w_{t t}, T w_{t p}, T w_{p p}$, and $T w_{p t}$ are the water starting time constants to accommodate the interaction between the turbine and pump or vice versa.

Equation (5) represents the interactions between the turbine and pump. To accommodate multiple units, this can be expanded in a similar manner [21]. The non-linear relation between gate, head and discharge is given by:

$$
q_{t}=G \sqrt{h}
$$

where $G$ is the turbine or pump gate.

The turbine is equipped with a PIDGOV type governor turbine model that controls the main inlet valves of the turbine and that of the pump. The non-linearity between the gate and power required has been ignored. The characteristics of the turbine and pump are simulated by:

$$
P_{m}=A_{t} h\left(\left(q-q_{n l}\right)\right)-D G \Delta \omega,
$$

where $\Delta \omega$, and $q_{n l}$ define the speed deviation from synchronous speed and the no load discharge required to maintain 0 power output while meeting all losses and yet maintain synchronism; $D$ and $A_{t}$ define the damping and power coefficients of the turbine to account for turbine characteristics; and $P_{t}$ and $P_{p}$ define the power output of the turbine and pump. 


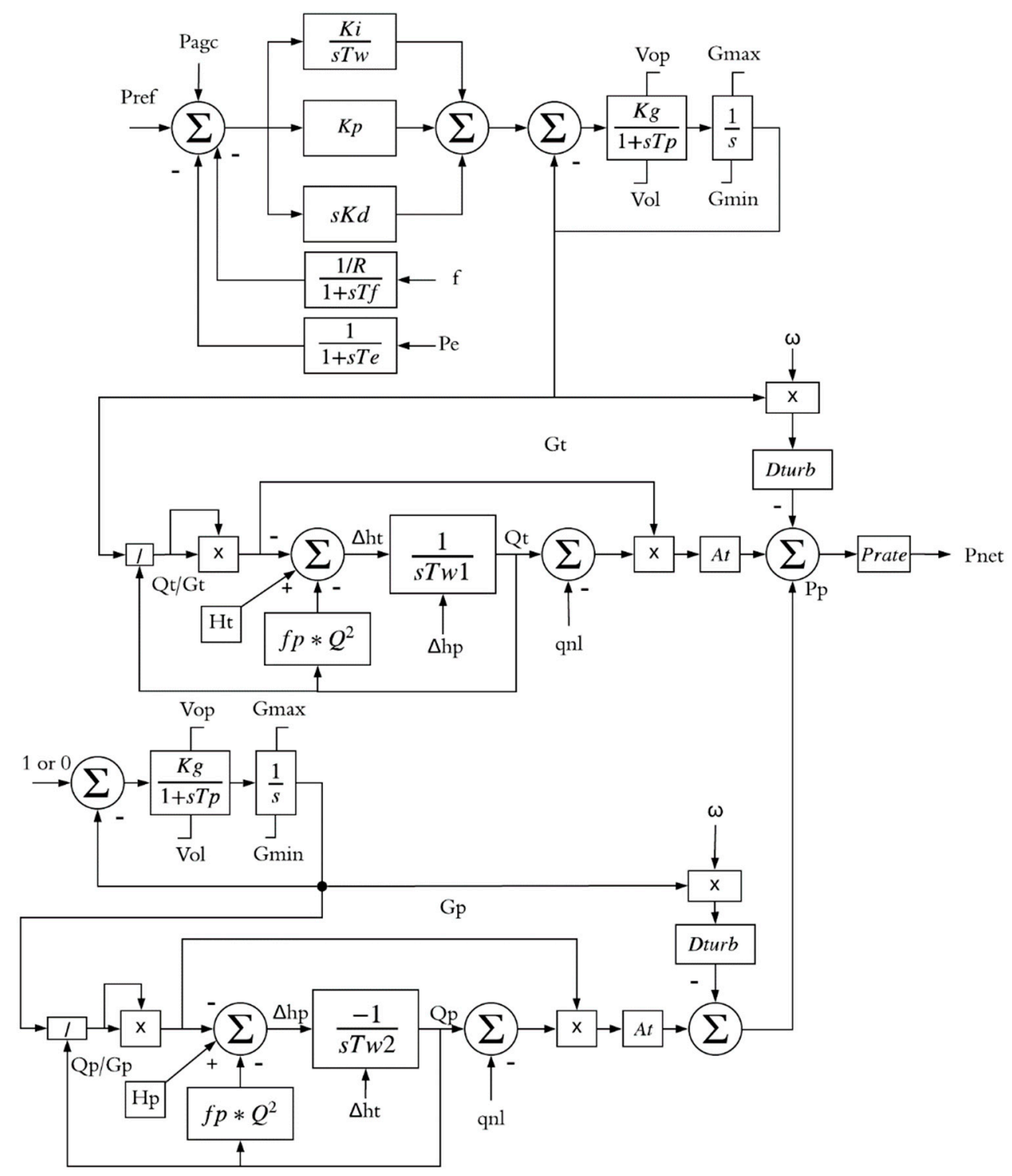

Figure 3. Dynamic model of TPSH with a PID governor for the turbine.

This model accounts for the no-load losses of water and the frictional losses. The model uses the coefficient $A_{t}$ to relate discharge to the mechanical power output,

$$
A_{t}=\frac{\text { Turbine MW rating }}{(\text { Generator MVA rating }) h r\left(q-q_{n l}\right)} .
$$

Equations (5)-(7) can be repeated for the pump in a similar way. The net power from the system is the sum of the pump power and turbine power, which is also the shaft power that is given to the electrical machine,

$$
P_{\text {shaft }}=P_{t}+P_{p}
$$

While the turbine accepts continuous gate commands, the pump accepts open and close commands. This governor turbine system is then connected to a salient pole machine model. The pump and turbine heads are modeled, respectively, by:

$$
H_{p}=\left[H_{0}+H_{1}(q)+H_{2}(q)^{2}\right](1+\Delta \omega)^{2},
$$




$$
H_{t}=1\left(H_{p}<1\right)+H_{p}\left(H_{p}>1\right) .
$$

Equation (9) can be obtained by identifying the characteristics of the pump given by the manufacturer. Equation (10) states the possibility of head at turbine entrance being greater than 1 due to system frequency fluctuations and pump speed variations. However, since the pump acts against a rated head produced by the upper reservoir, the head at the turbine entrance cannot be less than 1 .

\section{The Test System, Simulation, and Solver}

Figure 4 demonstrates the test system used to compare the dynamic behavior of TPSH and CPSH plants. The IEEE 9-bus system was modeled with governors to represent system dynamics. The system consists of three thermal plants equipped with IEEE-T1 governor systems with similar parameters but varying capacities [24]. The exciter system and voltage dynamics were assumed to be unaffected. The system parameters can be found in Appendix A.

To realize the effect of the loss of inertia, the thermal plant at bus 1 rated $500 \mathrm{MW}$ was replaced by a PV plant of equal capacity and a CPSH plant of $500 \mathrm{MW}$ was placed at bus 7 to form the baseline cases. For the purpose of comparison, the CPSH was replaced by a TPSH of $500 \mathrm{MW}$ with the governor and turbine structure as indicated in Figure 3. CPSH was simulated using the governor turbine structure as indicated in Figure 3 with the turbine set-point as 0 and the clutch $c 1$ disengaged. Simulating the CPSH the water starting time matrix was also modified to represent a single value $T w_{p p}$.

MATLAB code has been used to reconstruct the differential equations relevant to each block. The equations are then initialized and simulated. To simulate the system, a runge-kutta 4 solver was implemented. The use of this solver helps simulate all differential equations and accommodate the time varying inertia of the shaft, which would not be convenient in Simulink.

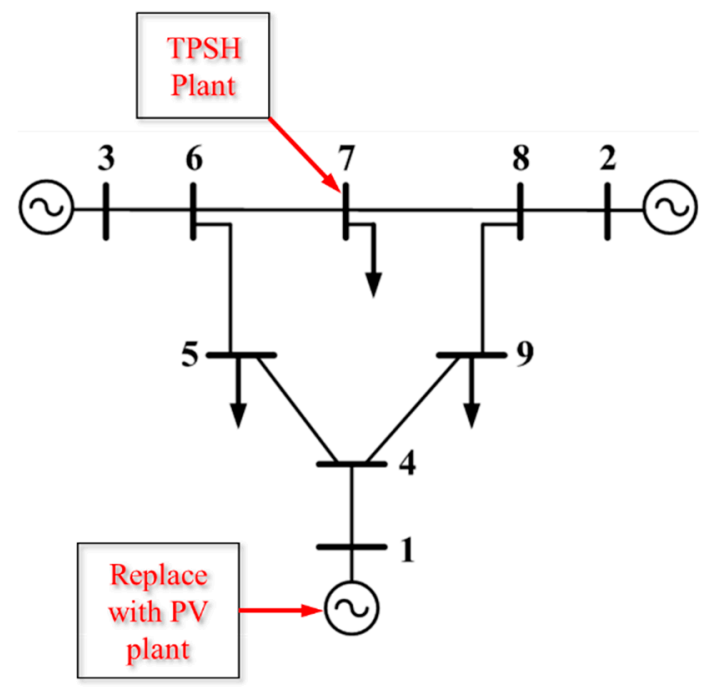

Figure 4. IEEE 9-bus test system indicating PV and PSH plants.

\section{Results and Discussion}

The test cases analyzed here focused mainly on the pump mode operation of the plant. In the generating mode the TPSH and the CPSH were basically the same as they both had governor control of the turbine. The difference, however, was that the TPSH employs a turbine rather than a pump-turbine, which enables it to operate over a wider range of power output.

\subsection{TPSH-HSC Reference Tracking}

Reference tracking was examined to understand the regulatory capability of TPSH in the pump mode using HSC and observe the expected non-linear characteristics of the hydro plant. Power 
references were provided to the plant and the plant tracks the references. The tracking performance of the plant in the pump mode has been displayed in Figure 5. At $t=40 \mathrm{~s}$ a step of 0.5 was applied, followed by a step of 0.9 at $t=100 \mathrm{~s}$, and 0.75 at $t=175 \mathrm{~s}$.

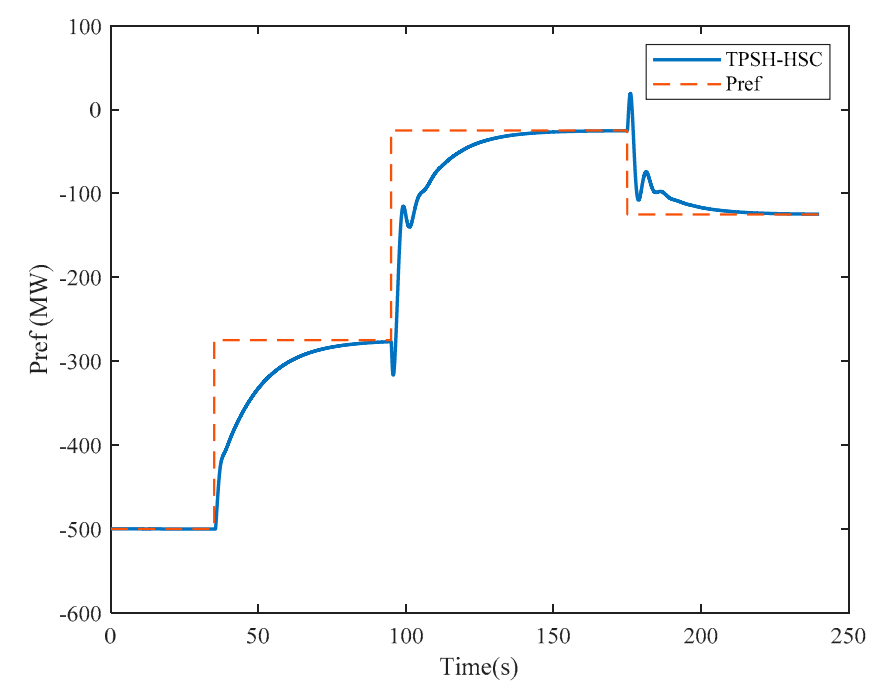

Figure 5. Reference tracking performance during the HSC mode. Negative power indicates pumping mode.

The reverse response behavior of the turbine was visible at $t=100 \mathrm{~s}$ and at $t=175 \mathrm{~s}$. The extent or degree of reverse response (non-linearity) increased as the loading level increased, which was mainly because of the change in effective water time constant. More details about such behavior can be found in [25].

\subsection{Baseline Analysis of Test System in Pump Mode of CPSH}

This baseline analysis answers the question as to what happens when large capacity PV farms were added to the system in the presence of a CPSH operating as a pump. The addition of the PV farm caused the retirement of a similar capacity thermal plant or exclusion of the thermal plant from scheduling. However, this resulted in the loss of inertia and to make matters worse, removed the primary and secondary frequency response services that were provided by the thermal plant. This situation was simulated by removing the $500 \mathrm{MW}$ thermal governor and plant from the system and adding a $500 \mathrm{MW}$ PV farm into the system whose dispatch was adjusted to match that of the thermal plant that it replaced. The system inertia was reduced by $3 \mathrm{~s}$. The steady-state dispatch value was obtained through simulation without the PV farm. The size of the test system did not allow the simulation of a plant trip so load change from $33 \%$ to $66 \%$ was simulated to the system at $50 \mathrm{~s}$, which caused the system frequency to drop significantly as to initiate governor action.

Before the addition of RES the frequency nadir was $59.72 \mathrm{~Hz}$. Figure 6a reveals that when the system inertia was reduced and primary frequency services previously provided by plant 3 (Appendix A) existed no more, the frequency nadir now decreased to $59.68 \mathrm{~Hz}$. The usual frequency limit set by FERC was $\pm 0.5 \mathrm{~Hz}$ hence the system was not in critical condition as to trigger load shedding or the tripping of PV inverters but the possibility of such events was valid in the face of further reduction of inertia with further addition of RES. Figure $6 \mathrm{~b}$ illustrates that under the given test conditions, the thermal plants experience more governor action. This will result in higher wear and tear or thermal governor. Hence, there is an ardent need for flexibility of network resources, which helps increase network resiliency to cope with such events. 


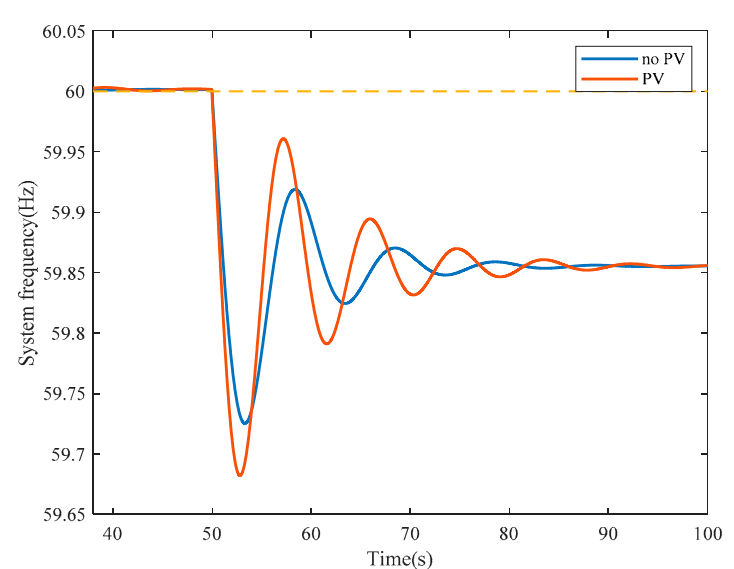

(a)

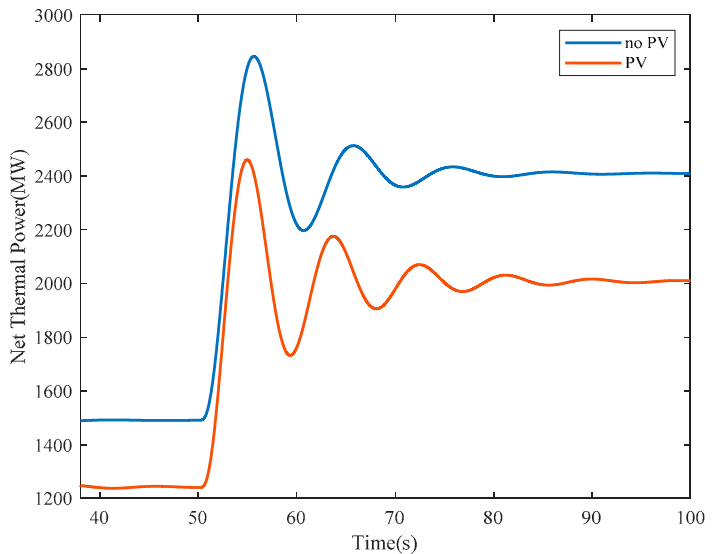

(b)

Figure 6. Baseline analysis of the test system in pump mode of $\mathrm{CPSH}$.

5.3. Comparison of Pump Mode Response from CPSH, TPSH in HSC, and Mode Change Capability of TPSH without $P V$

This case described the benefits of the ability of the TPSH system to change its mode rapidly from pumping mode to generation mode in case of severe disturbances. A comparison of the governor response of CPSH and TPSH and the unique capability of the TPSH to change its mode rapidly was studied here. This case did not consider PV.

System frequency dropped rapidly as the load was applied at $t=50 \mathrm{~s}$. The effect of the governor action of the thermal and hydro generators on system frequency was visible in Figure 7a. Thermal governors respond with instantaneous droop-based control through their IEEE-T1 governor system. The PIDGOV-based hydro action was visible when the TPSH-HSC was observed after $t=60 \mathrm{~s}$, where the system frequency climbed up to be higher than that with CPSH. The HSC mode helped the plant to respond to the AGC systems command and to the change in system frequency.

The TPSH-MC describes the effect of a mode change (MC). The plant trip detection is done with wide area monitoring systems and the command is sent to the TPSH plant. After receiving the command, the plant engages the turbine and HSC to change the mode. The algorithm then inspects if the turbine has saturated. If the turbine saturates at its maximum, the pump outlet gate is closed, and it is mechanically disconnected from the shaft with the help of a clutch.

The figures display the regulatory capability of the TPSH and its ability to change its mode. Figure $7 \mathrm{~b}$ shows the TPSH unit could move from $-500 \mathrm{MW}$ to $500 \mathrm{MW}$, thereby adding $1000 \mathrm{MW}$ of regulatory capability to the existing network. Figure 7c shows the response of the turbine. The turbine equipped with the PID governor ramped up to a rated capacity of 500MW. Figure $7 \mathrm{~d}$ shows that after the turbine saturated (in Figure 7c) at its rated output, the pump gate closed. As a result, pump power decreased to its minimum, after which the pump was disconnected from the shaft. 


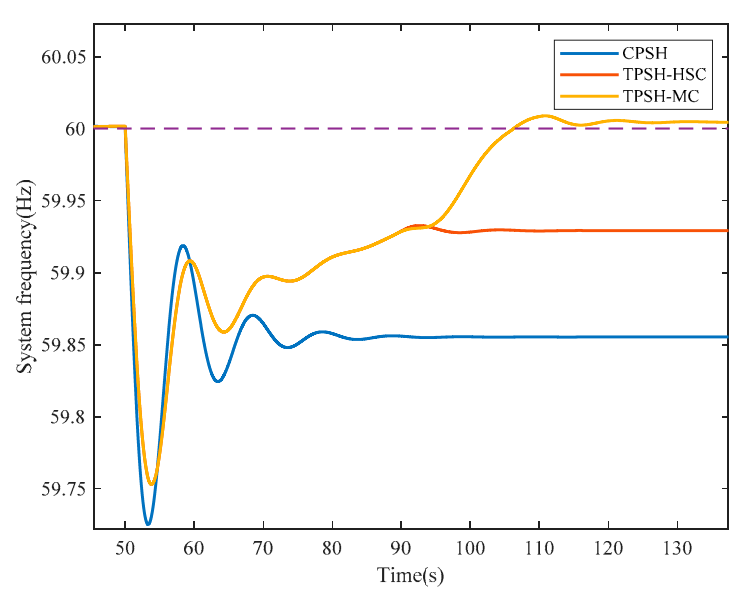

(a)

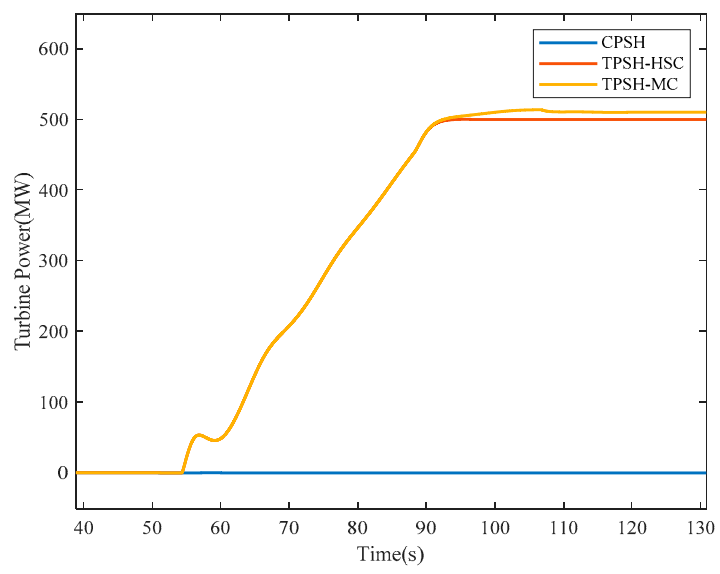

(c)

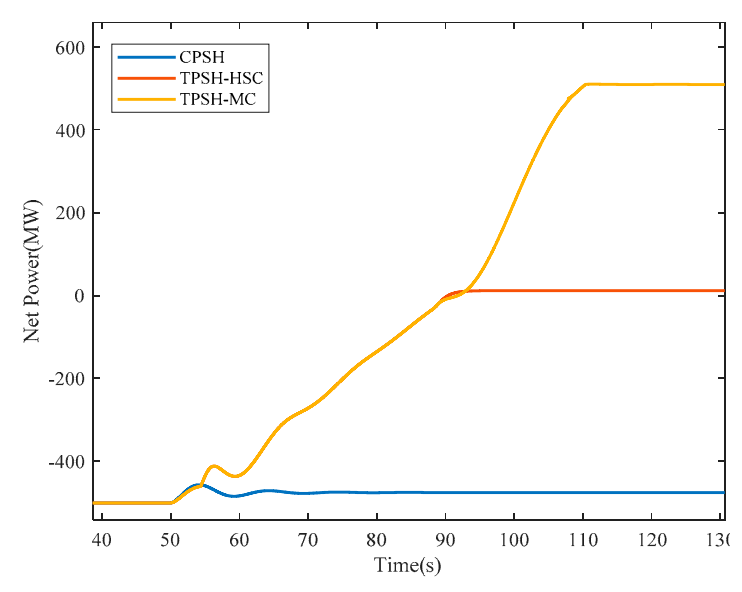

(b)

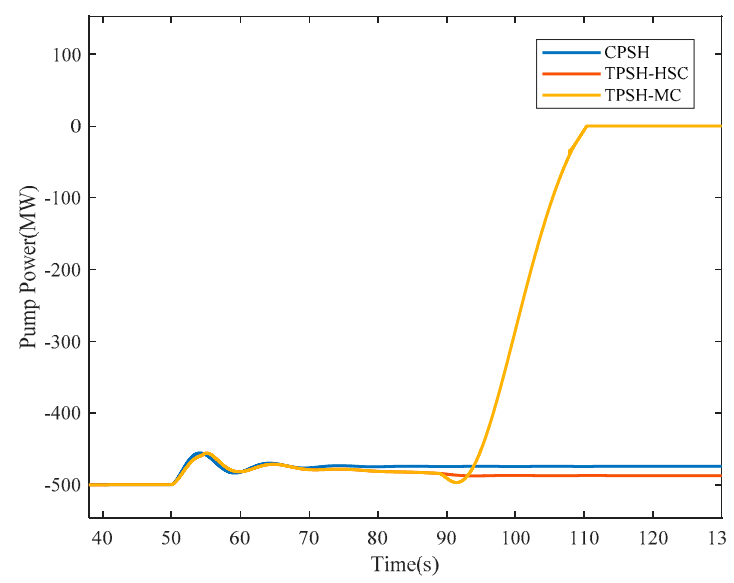

(d)

Figure 7. Comparison of CPSH, TPSH in HSC-mode (TPSH-HSC), and TPSH with HSC and mode change capability (TPSH-MC): (a) System frequency response; (b) net power production or consumption; (c) turbine power; and (d) pump power without PV.

5.4. Comparison of the Pump Mode Response from CPSH, TPSH in HSC-mode, and Mode Change Capability of TPSH in the Presence of PV

This case illustrates the contribution of TPSH over CPSH in a low inertia power system. Here, bus 1 was replaced with an equal capacity PV plant, which removed $3 \mathrm{~s}$ of inertia and the primary frequency services provided by the thermal plant.

With the HSC mode and the MC capability the frequency nadir was $59.75 \mathrm{~Hz}$ as compared to the $59.68 \mathrm{~Hz}$ of the case with CPSH. Until $t=90 \mathrm{~s}$, the effect of the PIDGOV hydraulic governor was evident in the frequency response after which the turbine governor saturated, and the pump gates were closed. Frequency oscillations were evidently reduced by the HSC mode and the MC capability added to the regulation as stated before and aided in system frequency recovery as shown in Figure 8. 


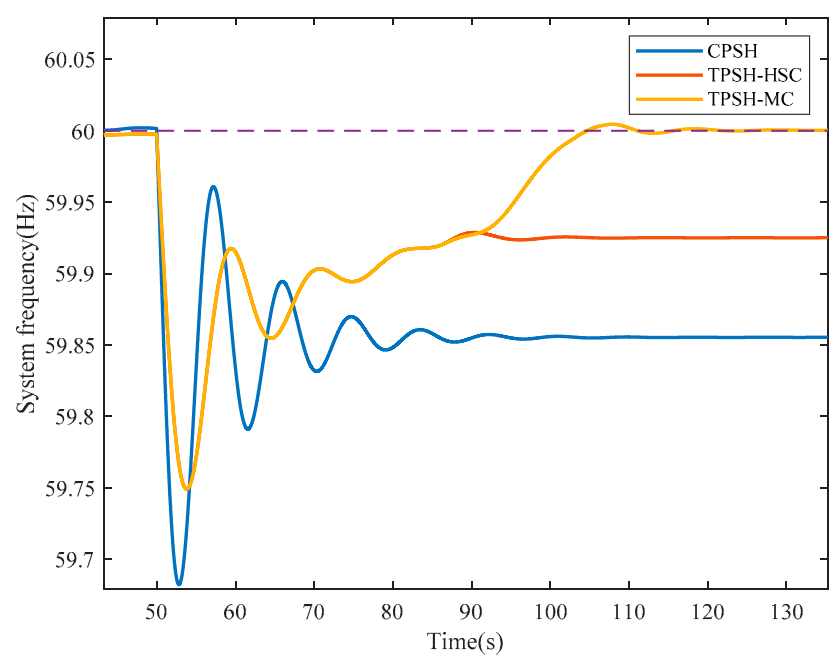

Figure 8. Comparison of CPSH, TPSH in HSC mode (TPSH-HSC), and TPSH with HSC and mode change capability (TPSH-MC) with PV.

\section{Conclusions}

The reduction in system synchronous inertia is a rising issue among power system engineers. In case of a disturbance in power balance, the low inertia power system can experience cascaded failures. To host more renewable energy and retain the resiliency of the system, pumped storage is a great alternative to electrochemical storage.

To understand the benefits of ternary pumped storage in a reduced inertia scenario, a dynamic model of ternary pumped storage plant was constructed and compared with that of a conventional pumped storage plant by integrating them to an IEEE 9-bus test-system simulated in MATLAB. Certain short-comings of similar works were accommodated. An increase in the load event was simulated to create a disturbance. Baseline analysis with and without PV indicated the fall in frequency nadir as the system inertia reduced when the disturbance was triggered. Results show that the hydraulic short circuit allowed the ternary pumped storage plant to track power references and hence provided regulation for the power system even in the pump mode. This capability to provide pump mode frequency regulation will be extremely helpful for modern power systems as $\mathrm{PSH}$ will also provide inertia to the system compared to electrochemical alternatives. Lastly, the HSC allows the TPSH plant to rapidly travel from the pumping mode to the generating mode, which provides twice the regulation capability in the case of severe outages in low inertia power systems.

Author Contributions: The following statements should be used, Conceptualization, S.N.; K.Y.L. and D.S.; Methodology, S.N. and D.S.; Software, S.N. and D.S; Validation, K.Y.L. and D.S.

Funding: This research received no external funding.

Conflicts of Interest: The authors declare no conflict of interest. The funders had no role in the design of the study; in the collection, analyses, or interpretation of data; in the writing of the manuscript, or in the decision to publish the results.

\section{Appendix A}

The following Table A1 describes the parameters of the hydraulic governor system for the TPSH. Identical parameters have been used for the CPSH system. 
Table A1. Parameters for the hydraulic governor turbine system.

\begin{tabular}{cc}
\hline Hydro Penstock, Turbine, and Pump Parameters & Value (unit) \\
\hline Turbine damping $(\mathrm{D})$ & $0.5 \mathrm{pu} / \mathrm{pu}$ \\
Water starting time for turbine $\left(T w_{t t}\right)$ & $2.13 \mathrm{~s}$ \\
Water starting time for pump $\left(T w_{t p}\right)$ & $2.13 \mathrm{~s}$ \\
Water starting time for turbine-pump $\left(T w_{p p}\right)$ & $0.13 \mathrm{~s}$ \\
Water starting time for pump-turbine $\left(T w_{p t}\right)$ & $0.13 \mathrm{~s}$ \\
Pump head discharge coefficients $\left(\mathrm{H}_{0}, \mathrm{H}_{1}, \mathrm{H}_{2}\right)$ & $700,-0.2,-0.001$ \\
Turbine and pump no-load losses $\left(q_{n l}\right)$ & $4.3 \mathrm{~m}^{3} / \mathrm{s}$ \\
Turbine and pump rating $\left(P_{\text {rate }}\right)$ & $500 \mathrm{MW}$ \\
Generator rating & $500 \mathrm{MVA}$ \\
Inertia for pump and turbine & $3 \mathrm{~s}, 3 \mathrm{~s}$ \\
\hline Hydro Governor Parameters & Value (unit) \\
\hline Servo motor gain $\left(K_{g}\right)$ & 0.98 \\
Servo motor Time constant $\left(T_{p}\right)$ & $0.2 \mathrm{~s}$ \\
Permanent droop $(\mathrm{R})$ & $0.05 \mathrm{pu}$ \\
Electrical power filter time constant $\left(T_{e}\right)$ & $5 \mathrm{~s}$ \\
Frequency filter time constant $\left(T_{f}\right)$ & $5 \mathrm{~s}$ \\
PID gains $\left(K_{p}, K_{i}, K_{d}\right)$ & $0.875,0.00025,0$ \\
Maximum opening $\left(\mathrm{V}_{\mathrm{op}}\right)$ and closing rate $\left(\mathrm{V}_{\mathrm{ol}}\right)$ & $0.1 \mathrm{pu} / \mathrm{s}$ and $-0.1 \mathrm{pu} / \mathrm{s}$ \\
\hline
\end{tabular}

\section{References}

1. Du, P.; Matevosyan, J. Forecast System Inertia Condition and Its Impact to Integrate More Renewables. IEEE Trans. Smart Grid 2018, 9, 1531-1533. [CrossRef]

2. Malley, E. Coal Power Plant Post-Retirement Options. Power Mag. 2016, 160, 60. Available online: https://www.powermag.com/coal-power-plant-post-retirement-options/?pagenum=6 (accessed on 6 July 2016).

3. Delhi to Replace Retired Thermal Power Plant with Solar Project. CleanTechnica 2019. Available online: https://cleantechnica.com/2019/07/22/delhi-to-replace-retired-thermal-power-plant-with-solar-project/ (accessed on 23 July 2019).

4. Brown, F. Ontario utility OPG makes room for solar at demolished coal power plant. Pv Mag. Int. 2018. Available online: https://www.pv-magazine.com/2018/03/01/ontarios-utility-opg-makes-room-for-solar-atdemolished-coal-power-plant/ (accessed on 06 December 2016).

5. Canadian Coal-Fired Power Plant Transformed into Solar Farm Yale E360. 2019. Available online: https://e360.yale.edu/digest/canadian-nanticoke-coal-fired-power-plant-transformed-in-solar-farm (accessed on 23 July 2019).

6. Scott, A. General Electric to Scrap California Power Plant 20 Years Early. 2019. Available online: https://www.reuters.com/article/us-ge-power/general-electric-to-scrap-california-power-plant-20-years-earl y-idUSKCN1TM2MV (accessed on 23 July 2019).

7. Aemo.com.au. 2019. Available online: https://aemo.com.au/-/media/Files/PDF/Response-of-Existing-PV-In verters-to-Frequency-Disturbances-V20.pdf (accessed on 06 December 2016).

8. Energy Storage Exchange. 2019. Available online: https://energystorageexchange.org/projects (accessed on 23 July 2019).

9. Antal, B.A. Pumped Storage Hydropower: A Technical Review. Master's Thesis, University of Colorado-Denve, Denver, CO, USA, 2014.

10. Applications of Energy Storage Technology. Energy Storage Association, 2019. Available online: http://energystorage.org/energy-storage/applications-energy-storage-technology (accessed on 23 July 2019).

11. Nrel.gov. 2019. Available online: https://www.nrel.gov/docs/fy10osti/47187.pdf (accessed on 23 July 2019).

12. Solomon, A.A.; Child, M.; Caldera, U.; Breyer, C. How much energy storage is needed to incorporate very large intermittent renewables? Energy Procedia 2017, 135, 283-293. [CrossRef]

13. Energy Storage Association. 2019. Available online: http://energystorage.org/ (accessed on 24 July 2019). 
14. Ferc.gov. 2019. Available online: https://ferc.gov/whats-new/comm-meet/2018/021518/E-1.pdf (accessed on 24 July 2019).

15. E. 841, Energy Storage Association Unveils Initial Assessment of Regional Grid Operator Compliance with Federal Energy Regulatory Commission Order 841. Energy Storage Association, 2019. Available online: http://energystorage.org/news/esa-news/energy-storage-association-unveils-initial-assessment-re gional-grid-operator (accessed on 24 July 2019).

16. Pumped Hydro-Power. Energy Storage Association, 2019. Available online: http://energystorage.org/energy -storage/energy-storage-technologies/pumped-hydro-power (accessed on 25 July 2019).

17. STENSEA-Storing Energy at Sea, Fraunhofer-Institut für Energiewirtschaft und Energiesystemtechnik. 2019. Available online: https://www.iee.fraunhofer.de/de/projekte/suche/laufende/stensea-storing-energy-at -sea.html (accessed on 23 July 2019).

18. Pilot Project-Max Bögl Wind, AG. Max Bögl Wind AG 2019. Available online: https://www.mbrenewables.c om/en/pilot-project?cn-reloaded=1 (accessed on 25 July 2019).

19. Gravity Power Module. Energy Storage. Grid-Scale Energy Storage. 2019. Available online: http://www.gravit ypower.net/ (accessed on 25 July 2019).

20. Nag, S.; Lee, K. DFIM-Based Variable Speed Operation of Pump-Turbines for Efficiency Improvement. IFAC PapersOnLine 2018, 51, 708-713. [CrossRef]

21. Kratirov, V.; Guzwoski, L. Modelling Ternary Pumped Storage Units; Argonne National Laboratory: Oak Ridge, TN, USA, 2013.

22. Dong, Z.; Nelms, R.; Muljadi, E.; Tan, J.; Gevorgian, V.; Jacobson, M. Development of dynamic model of a ternary pumped storage hydropower plant. In Proceedings of the 2018 13th IEEE Conference on Industrial Electronics and Applications (ICIEA), Wuhan, China, 31 May-2 June 2018; pp. 656-661. [CrossRef]

23. Demello, F.P.; Koessler, R.J.; Agee, J.; Anderson, P.M.; Doudna, J.H.; Fish, J.H.; Hamm, P.A.; Kundur, P.; Lee, D.C.; Rogers, G.J.; et al. Hydraulic turbine and turbine control models for system dynamic studies. IEEE Trans. Power Syst. 1992, 7, 167-179. [CrossRef]

24. Report, I. Dynamic Models for Steam and Hydro Turbines in Power System Studies. IEEE Trans. Power Appar. Syst. 1973, 92, 1904-1915. [CrossRef]

25. Pradhan, S.K.; Tripathy, S.K. Dynamic stability improvement of a hydraulic turbine generating unit using an optimal PID controller. In Proceedings of the 2015 International Conference on Industrial Instrumentation and Control (ICIC), Pune, India, 28-30 May 2015; pp. 115-120. [CrossRef]

(C) 2019 by the authors. Licensee MDPI, Basel, Switzerland. This article is an open access article distributed under the terms and conditions of the Creative Commons Attribution (CC BY) license (http://creativecommons.org/licenses/by/4.0/). 